\title{
Omphalocele: experience in the African tropics
}

\author{
F. NWABUEZe IHEKWABA \\ M.B., F.R.C.S. \\ The Department of Surgery, University College Hospital, Ibadan, Nigeria
}

\begin{abstract}
Summary
Omphalocele, the congenital anomaly of the anterior abdominal wall in the newborn, is a serious condition with a grave prognosis. Sac rupture, occurring in $25 \%$ of cases in Ibadan is associated with a high mortality. Although its embryogenesis is now better understood, its underlying aetiology remains obscure. Prematurity and low birth weight have no causal relationship to the condition, but a preponderance among the lower socio-economic groups in Ibadan is observed. Thirtythree cases seen over a 5-year period at the University College Hospital, Ibadan, Nigeria, constitute an unusually high incidence, suggesting that the condition may be aetiologically related to umbilical hernia which is known to be commoner in African than in Caucasian infants. Overall treatment results remain unsatisfactory for all types and mortality is still high. In those centres, particularly in the developing countries with scarce resources, conservative management should be the primary treatment modality for all intact sacs but staged procedures utilizing prosthetic materials should be reserved for the large ruptured sac.
\end{abstract}

\section{Introduction}

Omphalocele (syn. exomphalos) meaning literally 'umbilical hernia' is a serious congenital anomaly of the newborn infant. It is a surgical emergency. Usually associated with a poor prognosis except in the comparatively small ones, treatment was for long considered to be hopeless until Hey in 1803 reported the first successful repair. Hamilton's success in 1806 added a new impetus to the surgical attempts of the period, but Scarpa's (1812) efforts, however, were not so rewarding: he concluded that the anomaly was almost always fatal attributing his poor results to the often associated congenital anomalies and to difficulties in reducing the large hernia. A century and half has passed since those early efforts, but we do not appear to have improved much upon those depressing conclusions. Current estimates of the mortality rate have varied from 30 to $60 \%$ for all types, although a few centres in Europe and America are now reporting improved survival figures in selected cases.
Published experience with the management of this condition among African infants is unknown. This review was undertaken to ascertain the extent of the problem of omphalocele, and especially the larger problem of the ruptured omphalocele in African children.

\section{Embryology}

The embryological development of the omphalocele has been well defined (Dott, 1932; Margulies, 1945; Duhamel, 1963). Two clinical types, the 'small' (omphalocele minor), and the 'large' (omphalocele major), are recognized. They have different origins. The small omphalocele with a ring diameter of $4 \mathrm{~cm}$ or less, may be considered a hernia into the umbilical cord. The umbilical cord arises from the apex of the sac. The umbilical ring is widened, although it is normally placed. It is the failure of the umbilical ring to contract following the return of the intestines at the 10th week of development which leads to hernia into the umbilical cord. Thus the sac contains only gut, very rarely liver or other solid organs.

Omphalocele major arises from failure of early embryonic (3-9 $\mathrm{mm}$ stage) folding of the body of the embryo. Closure of the anterior abdominal wall employs 4 folds - cephalic, caudal and 2 lateral folds. Normally rapid growth of the mid-gut occurs between the 6th and 12th week of development when the entire mid-gut lies extra-coelomically. From their early embryological studies, Dott (1932) and Margulies (1945) and later Duhamel (1963) relate the large omphalocele to failure of return of the eviscerated organs owing to failure of the lateral folds to close during this period. Kermauner's view, put forward as long ago as 1909 , probably still has merit. He argued that the developmental error occurred much earlier, at the beginning of the third week of development and related this error to growth disturbances which occur in the myotomes at this period.

\section{Material and methods}

The case files of all newborn infants with the diagnosis seen during the 5 years 1973-1978 at 
University College Hospital, Ibadan, Nigeria, were studied. Altogether there were 37 patients. This number does not include those with gastroschisis. Owing to incomplete or lost records, 4 patients were excluded from the study; thus 33 patients' records were available for analysis. All the surviving cases had been followed-up for periods ranging from 5 months to 4 years.

\section{Results}

Age and sex

The age range on arrival in hospital was 5-72 hr. Twenty-four of the 33 infants $(72.7 \%)$ did not obtain any hospital therapy earlier than $36 \mathrm{hr}$. There were 17 males giving an equal sex incidence.

\section{Incidence}

Owing to a lack of a central register of births, the true prevalence per number of live births of this anomaly in the Ibadan region is not known. What this study shows is a hospital incidence based on the admissions list through the emergency department of one hospital. This department records a total annual admission of 12000 children. The 33 cases found in the 5-year period under review thus constitute a hospital incidence of one per 1818 admissions.

\section{Clinical types of omphalocele}

The state of rupture or non-rupture of the sac permits the 2 embryological types to be further divided into the small unruptured (8 cases), small ruptured (4 cases); the large unruptured (12 cases), and the large ruptured ( 9 cases). The small type had an umbilical ring diameter of $4 \mathrm{~cm}$ or less, while the large type included all those with a diameter greater than this figure. These types and the sex relationships are indicated in Table 1 and Fig. 1.

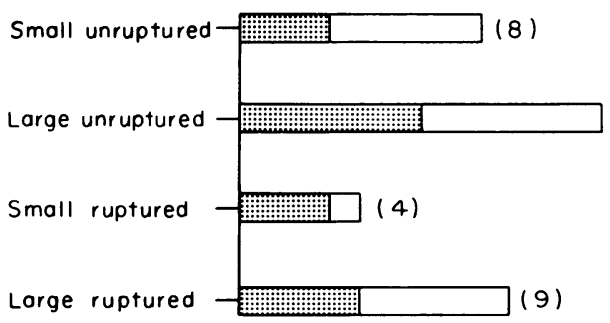

FIG. 1. Histogram showing types of omphalocele. 圈, female (16); $\square$, male (17).

\begin{tabular}{|c|c|c|}
\hline Type of omphalocele & $n$ & $(\%)$ \\
\hline $\begin{array}{l}\text { minor (small) } \\
\text { major (large) }\end{array}$ & $\begin{array}{l}12 \\
21\end{array}$ & $\begin{array}{l}(36) \\
(64)\end{array}$ \\
\hline
\end{tabular}

Sac content

The presence or absence of liver within the large omphalocele is indicated in Table 2.

TABLE 2. Omphalocele major. Presence or absence of liver in sac

\begin{tabular}{crr}
\hline Sac content & $n$ & $(\%)$ \\
\hline Present & 12 & $(57)$ \\
Not present & 9 & $(43)$ \\
\hline
\end{tabular}

\section{Birth weight and maturity}

Five patients including 4 who were premature hâ a birth weight which was less than $2.5 \mathrm{~kg}$. Foür died. Eleven of 24 with a birth weight greater than $2 \cdot 5 \mathrm{~kg}$ did not survive (Table 3 ).

TABLE 3. Birthweight, prematurity and mortality in 29 cases of omphalocele

\begin{tabular}{crcc}
\hline $\begin{array}{c}\text { Birthweight } \\
(\mathrm{kg})\end{array}$ & $n$ & Premature & Mortality \\
\hline$<2 \cdot 5$ & 5 & 4 & $4(80 \%)$ \\
$\geqslant 2 \cdot 5$ & 24 & 2 & $11(46 \%)$ \\
\hline
\end{tabular}

\section{Social class}

All 26 cases where it was possible to ascertain th parents' occupations were in the lower socie economic classes (semi-skilled and unskill workers). Most of the fathers were either farm labourers, carpenters or bricklayers. Nearly all the mothers were petty traders selling wares ranging from kola nuts to pepper.

\section{Blood group and haemoglobin genotype}

The pattern of blood group distribution in infants who were tested was very variable. Many of the mothers were not available for study. The Hbs gene (sickle-cell haemoglobin) was absent from cases tested.

\section{Associated anomalies}

Five types of anomaly were detected in $\frac{D}{18}$ patients (Table 4). Malrotation, present in

TABLE 4. Associated anomalies of omphalocele

\begin{tabular}{lr}
\hline \multicolumn{1}{c}{ Anomaly } & $n$ \\
\hline Malrotation & 10 \\
Beckwith-Wiedemann syndrome & 4 \\
Congenital heart disease & 2 \\
Colon hamartoma & 1 \\
Small bowel atresia & 1 \\
\hline
\end{tabular}


TABLE 5. Treatment and mortaliity in 33 cases of omphalocele

$\left.\begin{array}{llrl}\hline \multicolumn{1}{c}{\text { Type }} & \multicolumn{1}{c}{\text { Treatment }} & n & \multicolumn{1}{c}{\text { Mortality }} \\ \hline \begin{array}{l}\text { Omphalocele minor } \\ \text { unruptured }\end{array} & \text { Non-operative } & 8 & 0 \\ \text { ruptured } & \begin{array}{c}\text { Layered closure } \\ \text { (one-stage) }\end{array} & 4 & 1(25 \%)\end{array}\right\}(8 \cdot 3 \%)$

ruptured cases, was associated with one case of small bowel atresia, and one case of colonic hamartoma. The syndrome of omphalocele, macroglossia and gigantism (Beckwith-Wiedemann) was noted in 4 cases.

\section{Treatment and mortality}

Nineteen unruptured cases were treated by the application of $2 \%$ aqueous mercurochrome on alternate days. Only one large unruptured sac was treated by surgery. The patient survived. All 13 patients with ruptured sacs had operative treatment. The one-stage layered form of repair was employed for the small ruptured sacs while a simple skin closure as part of a planned 2-stage procedure was reserved for the large omphaloceles. Fourteen children who survived primary treatment later proceeded to secondary repair of the resulting hernia, the majority of these between one and 2 years. They all survived this secondary procedure. The results of treatment are as shown in Tables 5, 6 and 7.

TABLE 6. Results of primary operative treatment for all types of omphalocele

\begin{tabular}{ccc}
\hline$n$ & Deaths & Mortality \\
\hline 14 & 9 & $64 \%$ \\
\hline
\end{tabular}

\section{Discussion}

Estimates of the incidence of omphalocele vary, ranging from the $1 / 5000$ live-births frequently reported by surgeons to $1 / 3200$ when the live-born and still-born cases are considered together (McKeown, MacMahon and Record, 1953; Soper and Green, 1961). Crude hospital incidence figures emanating from centres dealing with a predominantly Caucasian population range from 19 to 39 cases seen over a 10-year period (Soper and Green, 1961; Mahour, Weitzman and Rosenkrantz, 1973; Aitken, 1963; Firor, 1971). Reports on the incidence of this condition in an African population are unknown. This study, at one hospital centre with a total annual admission list probably as great as those admitted into the European centres and which shows a hospital incidence of 33 in a 5 -year period, suggests that the condition is probably commoner among the African population studied. This finding raises the suspicion that the condition may be aetiologically related either geographically or racially to umbilical hernia which is known to occur more often in African than in Caucasian infants (Crump, 1952).

The role of predisposing factors in the causation of omphalocele remains unclear. Low birth weight and prematurity are not known to be causally related to the condition. In this study, only $17 \%$ of the neonates (5 of 29) had a birth weight which was $<2.5 \mathrm{~kg}$; a finding very much at variance with the quoted figures of $50-60 \%$ from European and American centres (Mahour et al., 1973; Colombani and Cunningham, 1977). Study of the socioeconomic status of the children's parents in this condition showed that the vast majority of the parents belonged to the lower strata. The significance of this finding is unknown. Analysis of the blood group distribution showed no definable pattern, nor did analysis of the genotypic distribution for sicklecell haemoglobinopathy.

TABLE 7. Results of secondary repair of the resulting hernia

$\left.\begin{array}{cccl}\hline \begin{array}{c}\text { Type of } \\ \text { omphalocele }\end{array} & \begin{array}{c}\text { Number surviving } \\ \text { primary treatment }\end{array} & \begin{array}{c}\text { Secondary } \\ \text { repair }\end{array} & \text { Mortality } \\ \hline \text { minor } & 11 & 9(81 \%) \\ \text { major } & 6 & 5(83 \%)\end{array}\right\} 0$


The size of the defect, clearly the greatest independent factor influencing prognosis, was significant in this study. The majority of cases belonged to the 'major' type $(64 \%)$, a type that is frequently associated with other congenital anomalies (Colombani and Cunningham, 1977); it accounted for $71 \%$ of the deaths in these series. Rupture in this type of omphalocele carried a particularly poor prognosis in the population studied.

The association of omphalocele with macroglossia (Beckwith syndrome) occurring in 4 cases is well recognized (Irving, 1967). Two of the 4 infants with this condition did not survive primary treatment. The other survivors, followed-up for 1.5 and 3.5 years respectively made satisfactory progress. Only one of these came to secondary repair of his moderate sized hernia.

Methods for the management of omphaloceles have varied from the conservative for the small intact sac to surgery either of the one-stage, or the 2-stage variety for the other types (Gross, 1948; Schuster, 1967). Owing to the unacceptably high mortality ranging from $40 \%$ to $80 \%$ for the surgical treatment of the large intact sacs, it was decided at Ibadan to follow the recommendation first suggested by Grob (1963) by painting the intact sac with chemical substances in order to allow undisturbed epithelialization of the defect and the growth of the abdominal cavity to receive the eviscerated organs. Experience at this centre confirms this improvement in the results when the intact sac was painted with mercurochrome. In 20 patients with the unruptured sac, 19 of whom were treated conservatively, there were 7 deaths, a mortality of $35 \%$. This high level of patient loss was thought to have been due to undiagnosed associated lethal gastrointestinal malformations such as malrotation, volvulus, atresia, etc. and cardiac lesions, often associated with these omphaloceles (Aitken, 1963; Grob, 1963; Irving, 1967).

Sac rupture, a grave complication which materially worsens the prognosis in omphalocele major may occur antenatally, during labour or after delivery. Factors leading to rupture are unknown. Although the presence of liver within the sac is a factor of great significance in prognosis (Soper and Green, 1961), liver within the sac per se is not known to predispose to sac rupture.

Management of the large ruptured omphalocele is fraught with difficulties and, at Ibadan, has not yielded the desired satisfactory results. Surgeons who undertake the treatment of these neonates here know that the task is a difficult one. These children arrive in hospital in an enfeebled, dehydrated condition, usually after a long, delayed journey and exposed to all manner of insults, including some previous attention by herbalists. Those born prema- ture have the attendant problems of liver immaturiकy and poor temperature control. Many have not been fed for 24-48 hr because of the fear of the mother to feed a baby whose intestines lie in the exterion. Infection and the often associated congenital matformations compound the plight of these children so that management resolves itself into one $\overline{\text { of }}$ salvage. In the antenatally ruptured sac in which tige mortality is estimated to be $100 \%$ (Rickham, 196\%) and which can be recognized by the typicalfy thickened, dry, lustreless intestines matted togeth and covered by a fibrinous exudate, it would seem that treatment in these cases is bound to fa Centres in the developing countries where resourç8s are scarce may find it expedient to offer no treatmegt at all to these types. The one-stage and 2-stage methods of treatment utilized for the post-nataly ruptured small and large sacs respectively hayd resulted in a $64 \%$ mortality. Death in these cases was attributed to infection and intra-abdomin crowding resulting in respiratory embarrassmera, inferior vena caval compression with reduction of venous return and cardiac failure, and impaired renal function. Proponents of the staged form off treatment aim to avoid these complications arg claim considerable improvement in their suryjval rates (Mahour et al., 1973; Aitken, 1963; Gi et al., 1968). This improvement may be enhanced the use of a prosthetic (Silastic, Teflon or Dacion) mesh to increase the capacity of the abdominil cavity until this latter has grown sufficiently tक enable the eviscerated organs to regain their "lost domain' (Schuster, 1967). Secondary repair of the resulting hernia was usually delayed and carried om during the period about the first birthday. Unfơ⿱ tunately, only $80 \%$ of infants with omphalocefe minor were brought back for this procedure, songe of the mothers accepting the hernia if it was not too large. Five children with the major defect w survived primary treatment $(83 \%)$ came to definitige surgery. They all survived.

The mortality rates in this series of $35 \%$ in the unruptured cases, and $64 \%$ for the surgically treated ruptured group and an overall rate of $48.4 \%$ conpares well with the reported experience in other centres. Soper and Green in 1961 reported mortality rate in the operated group of $43 \%$. Smith and Leix in 1966 returned a rate of $58.3 \%$. In 196\% Johnson recorded a rate of $80 \%$, but Girvan Webster and Shandling in 1974 showed an improve rate of $32 \%$. Colombani and Cunningham's recefit review in 1977 reported an overall mortality of $47 \%$

Further improvements in the survival after rupture of an omphalocele would seem to depeigd not only upon early surgical attention, but also upon developments in the pre-operative and pos?operative techniques of total care of the neonateक्ष, 
including the early and effective control of infection and respiratory and cardiovascular disturbances, hyper-alimentation (Mahour et al., 1973), and staged repair using a prosthetic mesh to assist closure of the large defect.

\section{Conclusions}

Omphalocele is a surgical emergency of the newborn infant and is associated with a high mortality.

A high incidence rate is noted in Ibadan and is greater than that reported from British and American centres. This condition predominates among children from lower socio-economic classes.

There seems to be an aetiological relationship of a geographical or racial nature between omphalocele and umbilical hernia. In third-world countries with scant resources, all unruptured sacs are best treated conservatively in the first instance. The large ruptured sac remains a surgical nightmare and improvements in its treatment will depend upon the availability of facilities for total care of the neonates as well as the utilization of staged procedures incorporating prosthetic materials.

\section{Acknowledgment}

The author is grateful to Professor E. O. Olurin for his encouragement and advice in the preparation of this paper.

\section{References}

Aitken, J. (1963) Exomphalos, analysis of a 10-year series of 32 cases. Archives of Disease in Childhood. 38, 126.

Colombani, P.M. \& Cunningham, M.D. (1977) Perinatal aspects of omphalocele and gastroschisis. American Journal of Diseases of Children, 131, 1386.

Crump, E.P. \& Pediat, J. (1952) Umbilical hernia. Journal of Pediatrics, 40, 214.

DotT, N. (1932) Omphalocele. Transactions of the Obstetric Society, 52, 105.
Duhamel, B. (1963) Embryology of exomphalos and allied malformations. Archives of Disease in Childhood, 38, 142.

FIROR, H.V. (1971) Omphalocele: an appraisal of therapeutic approaches. Surgery, 69, 208.

Gilbert, M.G., Mencia, L.F., Brown, W.T. \& Linn, B.S. (1968) Staged surgical repair of large omphaloceles and gastroschisis. Journal of Pediatric Surgery, 3, 702.

GiRvan, D.P., Webster, D.M. \& Shandling, B. (1974) The treatment of omphalocele and gastroschisis. Surgery, Gynecology and Obstetrics, 139, 222.

GroB, M. (1963) Conservative treatment of exomphalos. Archives of Disease in Childhood, 38, 148.

Gross, R.E. (1948) A new method for surgical treatment of large omphaloceles. Surgery, 24, 277.

Hamilton, J. (1806) In: The Anatomy and Surgical Treatment of Crural and Umbilical Hernia, Part II, p. 56. Longmans Green \& Co. Ltd, London.

Hey, W. (1803) Practical Observations in Surgery, p. 266. Cadell and Davies, London.

IRVING, I.M. (1967) Exomphalos with macroglossia. A study of eleven cases. Journal of Pediatric Surgery, 2, 499.

JoHnson, A.H. (1967) Omphalocele. American Journal of Surgery, 114, 279.

KERMAUNER, F. (1909) Die Missbildungen des Rumpfes, In: Die Morphologie der Missbildungen des Menschen und der Tiere (Ed by Schwalbe, E.), Vol. 3, p. 41. Gustav Fischer, Jena.

Mahour, G.H., Weitzman, J.J. \& Rosenkrantz, J.G. (1973) Omphalocele and gastroschisis. Annals of Surgery, $177,478$.

Margulies, L. (1945) Omphalocele (amniocele). American Journal of Obstetrics and Gynecology, 49, 695.

McKeown, T., MacMahon, B. \& Record, R.G. (1953) An investigation of 69 cases of exomphalos. American Journal of Human Genetics, 5, 168.

Rickman, P.P. (1963) Rupture of exomphalos and gastroschisis. Archives of Disease in Childhood, 38, 138.

ScARPA, A. (1812) Traité Pratique des Hernies. Gabon, Paris.

SCHUSTER, S.R. (1967) A new method for the staged repair of large omphaloceles. Surgery, Gynecology and Obstetrics, 125, 837.

SMITH, W.R. \& LeIX, F. Omphalocele. American Journal of Surgery, 111, 450.

SOPER, R.T. \& GREEN, E.W. (1961) Omphalocele. Surgery, Gynecology and Obstetrics, 113, 501. 